\title{
Prediction of ruminal volatile fatty acid proportions of lactating dairy cows based on milk odd- and branched-chain fatty acid profiles: New models, better predictions
}

\author{
A. M. Bhagwat, ${ }^{*}$ B. De Baets, ${ }^{*}$ A. Steen, $\dagger$ B. Vlaeminck, $\dagger$ and V. Fievez ${ }^{1}$ \\ ${ }^{*}$ KERMIT, Dept. of Mathematical Modeling, Statistics and Bioinformatics, Ghent University, Coupure links 653, 9000 Ghent, Belgium \\ †Laboratory for Animal Nutrition and Animal Product Quality, Ghent University, Proefhoevestraat 10, 9090 Melle, Belgium
}

\begin{abstract}
The volatile fatty acids (VFA) produced in the rumen and the proportions in which they are produced are important determinants of a ruminant's metabolism, but their monitoring requires rumen-fistulated animals, which is not feasible under practical conditions or in experimental setups at herd level. An alternative approach was suggested earlier, consisting of predicting the VFA proportions from measured odd- and branched-chain fatty acid concentrations in the milk with a linear model. Here, we have improved this strategy through the development and application of 2 new model structures: the quadratic model, containing quadratic terms and interactions, and the rational model, consisting of a ratio of linear expressions. Both were found to improve prediction accuracy significantly compared with the linear model. Although the quadratic model achieved the best prediction accuracy, the rational model has the interesting property that it takes the dependence of the 3 predicted VFA into account and guarantees that the 3 proportions add up to 1 . Adding a study effect to correct for a possible study bias in the multi-study data improved prediction substantially for all 3 methods. Our results demonstrate the potential of using milk odd- and branched-chain fatty acid concentrations to predict rumen VFA proportions.
\end{abstract}

Key words: volatile fatty acid, odd- and branchedchain fatty acid, modeling, prediction

\section{INTRODUCTION}

Lactating dairy cow digestion is strongly determined by the microbial population in the rumen. A large extent of the energy uptake by lactating dairy cows is in the form of VFA, synthesized in the rumen by this microbial population through fermentation of the feed (Bergman, 1990). Feed characteristics have been used

Received August 20, 2011.

Accepted February 22, 2012.

${ }^{1}$ Corresponding author: veerle.fievez@ugent.be to predict total amounts of VFA produced (Loncke et al., 2009), as well as molar proportions of different VFA (Morvay et al., 2011; Nozière et al., 2011). Especially, molar proportions are of interest from a nutritional point of view, as acetate (AC) and butyrate (BU) are lipogenic nutrients, whereas propionate (PR) is a glucogenic nutrient, with the 3 VFA representing the majority of total VFA. The relative proportions are also important from an environmental perspective, as their production either enhances (mainly AC) or decreases (mainly PR) methane emissions. Under experimental conditions, VFA proportions are traditionally assessed by determining VFA proportions of a multitude of rumen samples obtained daily from rumen-fistulated animals, esophageal tube or trocar, assuming these reflect production proportions. Such measurements show that VFA proportions vary significantly for different diets (Sutton et al., 2003).

Our research has focused on using milk FA profiles to determine fermentation patterns (Vlaeminck et al., 2006b; Craninx et al., 2008). A milk-based technique could make it possible to get information on VFA proportions when rumen sampling is not feasible (e.g., in herd-based experiments) and even under practical circumstances, rendering it possible to obtain data from many more animals. Milk FA that have been mainly targeted are odd- and branched-chain FA (OBCFA), which are predominantly synthesized by the rumen microbial population and carry a certain amount of information on the fermentation pattern from the rumen to the readily sampled milk. For instance, the bacterial membrane of amylolytic bacteria, which produce relatively more PR, shows a distinctive OBCFA profile compared with the membrane of fibrolytic bacteria, which are predominantly AC producers (Vlaeminck et al., 2006a).

Obviously, the potential for milk OBCFA to be used in dairy cattle management depends on the availability of a fast analytical method at a reasonable price. Although spectroscopy is considered superior over separatory techniques (such as GC) for the latter reason, they are not yet accurate enough to detect biologically 
relevant differences. Alternatively to routine spectroscopy and the slow GC reference methods, a reliable, semi-routine analytical GC approach to quantify milk OBCFA was proposed, which accomplished the separation of major FA present in milk fat, including the OBCFA, in less than 15 min (Gervais et al., 2011).

Whereas previously, a linear model (LIN) was used to predict the rumen VFA proportions from OBCFA levels in milk (Vlaeminck et al., 2006a), in the current manuscript we investigated 2 new modeling approaches: a model with quadratic terms and interaction effects (QUAD) and a model based on a rational model structure (RAT). The former has merit due to its more flexible model structure, whereas the latter better respects the proportional nature of the measurements. We first searched for the best OBCFA combination to include in both models, and then compared the performance of both modeling approaches using their respective best OBCFA subset. We also investigated the effect of adding a study effect to the model to account for differences in protocols used for VFA sampling and analysis.

\section{MATERIALS AND METHODS}

\section{Data Set}

Our data originate from 13 feeding trials with rumenfistulated lactating dairy cows, which can be grouped into 9 independent studies, resulting in a total of 224 coupled rumen VFA proportions and milk FA profiles (Table 1). Eleven trials (trials A-J and trial M) followed a Latin square design, of which 2 trials were incomplete. In the remaining 2 trials (trial $\mathrm{K}$ and $\mathrm{L}$ ), all animals underwent simultaneous and subsequent ration changes according to an acidosis induction scheme. For these trials, only rations that did not induce subacute acidosis were included in the data set.

For each ration-animal combination, various rumen samples were taken. Depending on the protocol, 2 (trial $\mathrm{M}$ ) to 15 (trials E and F) rumen samples were taken and analyzed daily. All VFA analyses were performed at the original research institutes where the experiments took place according to the methodology outlined in the corresponding papers (Table 1). Rumen sampling and VFA analyses of unpublished experiments were performed according to descriptions given by Vlaeminck et al. (2005). Due to the differences in rumen VFA sampling and analysis, we expected a study bias in the form of a different measurement offset or constant error per study cluster, and we modified the original models to account for this effect.

Milk samples were taken from 2 (trial M) up to 8 (trial C) milkings. Milk FA were all analyzed at our laboratory by GC as described by Vlaeminck et al. (2005).
Seven OBCFA from milk FA profiles were considered as possible inputs for a predictive model: iso $\mathrm{C} 13: 0$, iso $\mathrm{C} 14: 0$, iso $\mathrm{C} 15: 0$, anteiso $\mathrm{C} 15: 0, \mathrm{C} 15: 0$, iso $\mathrm{C} 16: 0$, and the sum of $\mathrm{C} 17: 0$ and $\mathrm{C} 17: 1$ cis-9. The latter is mainly synthesized from C17:0 in the mammary gland (Fievez et al., 2003). The FA iso C17:0 and anteiso C17:0 were omitted, because for some experiments they seemed to co-elute with trans- or cis-C16 MUFA during the GC analysis (Stefanov et al., 2010).

\section{LIN}

Vlaeminck et al. (2006b) suggested a linear relationship between VFA proportions in the rumen and OBCFA levels in the milk:

$$
\begin{aligned}
& \widehat{\mathrm{AC}}=\mathrm{a}_{0}+\sum_{\mathrm{i}=1}^{\mathrm{m}_{\mathrm{AC}}} \mathrm{a}_{\mathrm{i}} \cdot \mathrm{OBCFA}_{\mathrm{i}} ; \\
& \widehat{\mathrm{PR}}=\mathrm{p}_{0}+\sum_{\mathrm{i}=1}^{\mathrm{m}_{\mathrm{PR}}} \mathrm{p}_{\mathrm{i}} \cdot \mathrm{OBCFA}_{\mathrm{i}} ; \\
& \widehat{\mathrm{BU}}=\mathrm{b}_{0}+\sum_{\mathrm{i}=1}^{\mathrm{m}_{\mathrm{BU}}} \mathrm{b}_{\mathrm{i}} \cdot \mathrm{OBCFA}_{\mathrm{i}} .
\end{aligned}
$$

Here, $\widehat{\mathrm{AC}}, \widehat{\mathrm{PR}}$, and $\widehat{\mathrm{BU}}$ are the model predictions of the relative rumen proportions of $\mathrm{AC}, \mathrm{PR}$, and $\mathrm{BU}$, respectively, expressed in $\mathrm{mmol} /(\mathrm{mol}$ of $\mathrm{AC}+\mathrm{PR}+\mathrm{BU})$. Further, $\mathrm{OBCFA}_{i}$ is the level of the ith OBCFA in the milk fat, expressed in $\mathrm{g} / 100 \mathrm{~g}$ of FA methyl ester, excluding glycerol. Finally, $\mathrm{a}_{0}, \mathrm{a}_{\mathrm{i}}, \mathrm{p}_{0}, \mathrm{p}_{\mathrm{i}}, \mathrm{b}_{0}$, and $\mathrm{b}_{\mathrm{i}}$ are the model coefficients. Not all available OBCFA were used for each VFA, and the number of OBCFA included in the model is denoted by $\mathrm{m}_{\mathrm{AC}}, \mathrm{m}_{\mathrm{PR}}$, and $\mathrm{m}_{\mathrm{BU}}$ for $\mathrm{AC}$, $\mathrm{PR}$, and $\mathrm{BU}$, respectively.

\section{QUAD}

As biology is inherently nonlinear, a nonlinear model structure might be able to capture the dependencies between rumen VFA and milk OBCFA better. Therefore, we investigated the following QUAD, including quadratic terms and all pairwise interactions of OBCFA:

$$
\begin{aligned}
& \widehat{A C}=a_{0}+\sum_{i=1}^{m_{A C}} a_{i} \cdot \text { OBCFA }_{i}+\sum_{i=1}^{m_{A C}} \sum_{j=1}^{m_{A C}} a_{i j} \cdot \text { OBCFA }_{i} \cdot \text { OBCFA }_{j} \\
& \widehat{P R}=p_{0}+\sum_{i=1}^{m_{P R}} p_{i} \cdot \text { OBCFA }_{i}+\sum_{i=1}^{m_{P R}} \sum_{j=1}^{m_{P R}} p_{i j} \cdot \text { OBCFA }_{i} \cdot \text { OBCFA }_{j} ; \\
& \widehat{B U}=b_{0}+\sum_{i=1}^{m_{B U}} b_{i} \cdot \text { OBCFA }_{i}+\sum_{i=1}^{m_{B U}} \sum_{j=1}^{m_{B U}} b_{i j} \cdot \text { OBCFA }_{i} \cdot \text { OBCFA }_{j} \cdot
\end{aligned}
$$


Table 1. Overview of the 13 different feeding trials in the data set (related trials are grouped into the same study)

\begin{tabular}{|c|c|c|c|c|c|c|c|c|c|}
\hline $\begin{array}{l}\text { Trial } \\
\text { (study) }\end{array}$ & $\begin{array}{l}\text { Data } \\
\text { points } \\
\text { (no.) }\end{array}$ & $\begin{array}{l}\text { Cows } \\
\text { (no.) }\end{array}$ & $\begin{array}{c}\text { Lactation } \\
\text { stage } \\
(\mathrm{DIM} ; \pm \mathrm{SD})\end{array}$ & $\begin{array}{l}\text { Experimental } \\
\text { period }(\mathrm{d})\end{array}$ & Roughage & $\begin{array}{l}\text { Concentrate } \\
(\mathrm{kg} / \mathrm{d})^{1}\end{array}$ & $\begin{array}{l}\text { Experimental } \\
\text { design }\end{array}$ & Test objectives & Description \\
\hline A (1) & 21 & 6 & $185 \pm 75$ & 21 & $\begin{array}{l}\text { Grass, clover, alfalfa } \\
\text { silage, or mixed silages }\end{array}$ & 8 & $4 \times 6$ & $\begin{array}{l}\text { Evaluation of feed intake, milk } \\
\text { production, N utilization and fatty } \\
\text { acid composition of milk fat with } \\
\text { diets based on legumes silages }\end{array}$ & $\begin{array}{l}\text { Dewhurst et } \\
\text { al. (2003) }\end{array}$ \\
\hline B (2) & 16 & 4 & $145 \pm 37$ & 28 & Grass silage & $\begin{array}{l}\text { F:C ratios } \\
(80 / 20,65 / 35, \\
50 / 50,35 / 65)\end{array}$ & $4 \times 4$ & $\begin{array}{l}\text { Relationship between forage-- } \\
\text { concentrate ratio and feed } \\
\text { intake, supply and utilization } \\
\text { of nutrients in rumen }\end{array}$ & $\begin{array}{l}\text { Moorby et } \\
\text { al. }(2006)\end{array}$ \\
\hline C (3) & 16 & 4 & $130 \pm 24$ & 28 & Grass silage & 17 & $4 \times 4$ & $\begin{array}{l}\text { Relate site and extent of } \\
\text { degradation of three starch } \\
\text { sources, determined in vivo and } \\
\text { compared with nylon bag and } \\
\text { gas production technique }\end{array}$ & $\begin{array}{l}\text { Hindle et } \\
\text { al. }(2005)\end{array}$ \\
\hline D (4) & 16 & 4 & $275 \pm 22$ & 21 & Grass silage & 4.5 & $4 \times 4$ & $\begin{array}{l}\text { Assessment of effect of grassland } \\
\text { management on ruminal digestion }\end{array}$ & $\begin{array}{l}\text { Bruinenberg } \\
\text { et al. (2004) }\end{array}$ \\
\hline $\mathrm{E}+\mathrm{F}(5)$ & 50 & 5 & $\begin{array}{l}114 \pm 45(\text { Exp. 5) } \\
294 \pm 33 \text { (Exp. 6) }\end{array}$ & 21 & Grass + maize silage & TMR (50/50) & $5 \times 5$ & $\begin{array}{l}\text { Effect of varying forage (maize } \\
\text { vs. grass silage) and concentrate } \\
\text { (starch vs. fiber rich) source } \\
\text { on diurnal intake pattern and } \\
\text { milk fatty acid composition }\end{array}$ & $\begin{array}{l}\text { Abrahamse } \\
\text { et al. (2008) }\end{array}$ \\
\hline $\mathrm{G}+\mathrm{H}(6)$ & 17 & 3 & $308 \pm 142$ & 13 & Grass + maize silage & 5.1 & $3 \times 3$ & $\begin{array}{l}\text { Effect of starch content } \\
\text { of corn silage on rumen } \\
\text { fermentation pattern and milk } \\
\text { production characteristics }\end{array}$ & $\begin{array}{l}\text { de Brabander } \\
\text { et al. }(2004)\end{array}$ \\
\hline $\mathrm{I}+\mathrm{J}(6)$ & 8 & 2 & $284 \pm 101$ & 13 & Grass + maize silage & 5.1 & $2 \times 2$ & $\begin{array}{l}\text { Effect of starch degradability } \\
\text { of corn silage on rumen } \\
\text { fermentation pattern and milk } \\
\text { production characteristics }\end{array}$ & $\begin{array}{l}\text { de Brabander } \\
\text { et al. }(2005)\end{array}$ \\
\hline $\mathrm{K}(7)$ & 20 & 4 & $212 \pm 35$ & 14 & $\begin{array}{l}\text { Grass }+ \text { maize silage } \\
+ \text { grass seed hay }\end{array}$ & 4 & $\begin{array}{l}\text { First } 5 \text { periods } \\
\text { in } 6 \text {-period } \\
\text { acidosis }\end{array}$ & $\begin{array}{l}\text { Evaluation on ruminal } \\
\text { fermentation and milk fatty acid } \\
\text { profiles with diets containing } \\
\text { increasing amounts of quickly } \\
\text { fermentable carbohydrates }\end{array}$ & $\begin{array}{l}\text { Craninx et al. } \\
\text { (unpublished } \\
\text { results) }\end{array}$ \\
\hline L (8) & 48 & 12 & $246 \pm 103$ & 7 & Grass + maize silage & 10 to 16 & $\begin{array}{l}\text { First } 4 \text { periods } \\
\text { in } 6 \text {-period } \\
\text { acidosis }\end{array}$ & $\begin{array}{l}\text { Evaluation on ruminal } \\
\text { fermentation and MFA } \\
\text { profiles with diets containing } \\
\text { increasing amounts of quickly } \\
\text { fermentable carbohydrates }\end{array}$ & $\begin{array}{l}\text { Colman et } \\
\text { al. }(2011)\end{array}$ \\
\hline M (9) & 12 & 3 & $158 \pm 40$ & 21 & Grass + maize silage & 8 to 10 & $3 \times 4$ & $\begin{array}{l}\text { Effect of ration starch content on } \\
\text { fermentation pattern and milk fat }\end{array}$ & $\begin{array}{l}\text { Colman et } \\
\text { al. }(2011)\end{array}$ \\
\hline
\end{tabular}

${ }^{1} \mathrm{~F}: \mathrm{C}=$ forage:concentrate.

${ }^{2}$ M. Craninx, B. Vlaeminck, V. Fievez (Laboratory for Animal Nutrition and Animal Product Quality, Melle, Belgium), and H. van Laar (Nutreco Ruminant Research Centre, Boxmeer, the Netherlands). 


\section{RAT}

Neither of the previous models take the known dependence of the 3 VFA into account. When the proportion of $2 \mathrm{VFA}$ is predicted to be higher, the proportion of the third has to be lower by definition, and the sum of the $3 \mathrm{VFA}$ proportions should always equal 1,000 $\mathrm{mmol} / \mathrm{mol}$. Whereas LIN and QUAD cannot guarantee that these properties hold, the following RAT has them embedded in its model structure:

$$
\begin{aligned}
& \widehat{A C}=1,000 \frac{\sum_{i} a_{i} \cdot \text { OBCFA }_{i}}{\sum_{i_{i}} a_{i} \cdot \text { OBCFA }_{i}+\sum_{i} p_{i} \cdot \text { OBCFA }_{i}+\sum_{i} b_{i} \cdot \text { OBCFA }_{i}} ; \\
& \widehat{P R}=1,000 \frac{\sum_{i} p_{i} \cdot \text { OBCFA }_{i}}{\sum_{i_{i}} a_{i} \cdot \text { OBCFA }_{i}+\sum_{i} p_{i} \cdot \text { OBCFA }_{i}+\sum_{i} b_{i} \cdot \text { OBCFA }_{i}}
\end{aligned}
$$

The denominator is the same for all 3 expressions and is equal to the sum of the 3 numerators, which forces the sum of the 3 VFA ratios to be equal to 1 . The factor 1,000 is added to express the proportions in units of $\mathrm{mmol} /(\mathrm{mol} \mathrm{AC}+\mathrm{PR}+\mathrm{BU})$. We call this the rational model, as each of the VFA is modeled as a ratio of linear expressions.

\section{Estimating the Model Coefficients}

Those values of the model coefficients $\mathrm{a}_{0}, \mathrm{p}_{0}, \mathrm{~b}_{0}, \mathrm{a}_{\mathrm{i}}, \mathrm{p}_{\mathrm{i}}$, and $b_{i}$ in Equations 1 to 3 are sought that minimize the model's overall mean squared training error:

$$
\mathrm{MSE}^{\mathrm{TRAIN}}=\frac{1}{3 \cdot n} \sum_{\substack{\mathrm{VFA} \in \\\{\mathrm{AC}, \mathrm{PR}, \mathrm{BU}\}}} \sum_{k=1}^{n}\left(\mathrm{VFA}_{k}-\widehat{\mathrm{VFA}}_{k}^{\mathrm{TRAIN}}\right)^{2} .
$$

The symbols $\mathrm{VFA}_{k}$ and $\widehat{\mathrm{VFA}}_{k}^{\text {TRAIN }}$ represent the observed and predicted VFA proportions, respectively, for data point $k$ and MSE denotes the mean squared error. The superscript TRAIN indicates that the same data set was used to estimate model coefficients, as well as to calculate model predictions.

For Equations 1 and 2, with linear model coefficients, the function $\mathrm{lm}$ in the stats package of $\mathrm{R}$ ( $\mathrm{R}$ Development Core Team, 2011) was used. For Equation 3, with nonlinear model coefficients, 2 different optimization methods were used: the method of Nelder and Mead (1965) and the Broyden-Fletcher-Goldfarb-Shanno (BFGS) method (Broyden, 1970; Fletcher, 1970; Goldfarb, 1970; Shanno, 1970). Both are available in the stats package of the statistical computing language $R$ (R Development Core Team, 2011).

For Equation 3, multiplying all coefficients $\left(\mathrm{a}_{\mathrm{i}}, \mathrm{p}_{\mathrm{i}}\right.$, and $\mathrm{b}_{\mathrm{i}}$ ) by the same factor leads to an identical model, as the multiplication factors from numerator and denominator cancel. This means an infinite number of model coefficients results in identical model predictions, making the optimization problem ill posed. We tackled this issue by fixing the value of the last $b_{i}$ coefficient in the model at 1 . The required initial estimate is set equal to 1 for every coefficient, giving equal initial importance to each of the OBCFA. For both methods, we searched for a good choice for the maximum number of optimization iterations (MAXIT). This number has to be chosen adequately: too low can lead to underfitting, but too high brings a risk of overfitting, and both lead to bad prediction performance. We investigated MAXIT values of 100,500, and 2,500 for the Nelder-Mead method, and 500, 1,500, and 12,500 for the BFGS method. The lowest values were chosen as the defaults in the stats package in R (R Development Core Team, 2011), and the highest as 25 times the defaults.

\section{Quantifying the Prediction Performance Through Cross-Validation}

A model's prediction performance corresponds to its ability to make accurate and precise predictions for observations that were not used to estimate its coefficients. To quantify this out-of-box performance, we calculated the predicted VFA values with a cross-validation $(\mathbf{C}-\mathbf{V})$. We first divided our data into 7 folds, in such a way that the observations of each study are balanced over all folds. Then, we followed the strategy outlined in Figure 1. The figure shows 3 folds, but we used 7 , because this led to a perfectly balanced number of observations per fold $(224 / 7=32)$. In what follows, $\mathrm{VFA}_{k}$ and $\widehat{\mathrm{VFA}}_{k}^{\mathrm{C}-\mathrm{V}}$ denote the observed and the through $\mathrm{C}-\mathrm{V}$-predicted values of the VFA for data point $k$, respectively. More details on purpose and application of C-V can be found in Hastie et al. (2009).

From the predicted VFA values, the VFA-specific prediction accuracy was calculated in terms of the mean squared C-V error ( $\mathrm{MSE}_{\mathrm{VFA}}^{\mathrm{C}-\mathrm{V}}$, Equation 5), the root mean squared $\mathrm{C}-\mathrm{V}$ error $\left(\mathrm{RMSE}_{\mathrm{VFA}}^{\mathrm{C}-\mathrm{V}}\right.$, Equation 6), and the percentage of variance that could be predicted by the model $(\mathrm{Q} 2 \mathrm{VFA}$, Equation 7):

$$
\mathrm{MSE}_{\mathrm{VFA}}^{\mathrm{C}-\mathrm{V}}=\frac{1}{n} \sum_{k=1}^{n}\left(\mathrm{VFA}_{k}-{\widehat{\mathrm{VFA}_{k}}}^{\mathrm{C}-\mathrm{V}}\right)^{2}
$$




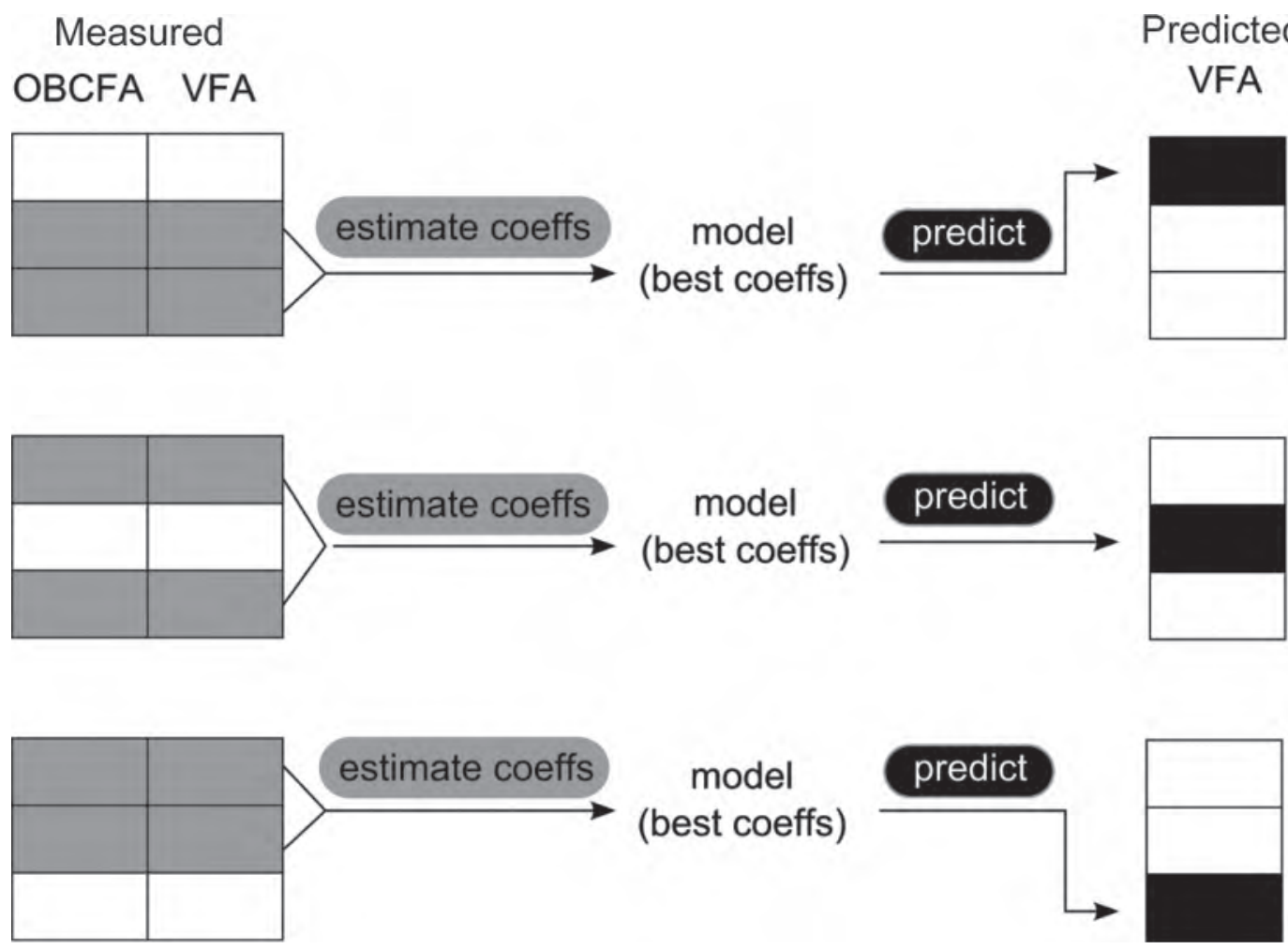

Figure 1. Cross-validation (C-V) of a model, illustrated on a 3-fold data set. Measured odd- and branched-chain FA (OBCFA) and VFA are shown on the left, predicted VFA on the right. In each $\mathrm{C}-\mathrm{V}$ step, first the best model coefficients are sought using all data folds except 1 (included folds are shown in gray), and the model with optimal coefficients is used to predict the VFA of the left-out fold (shown in black). This is repeated for each of the folds, such that 1 predicted value is calculated for each measured VFA. coeffs $=$ coefficients.

$$
\begin{gathered}
\mathrm{RMSE}_{\mathrm{VFA}}^{\mathrm{C}-\mathrm{V}}=\sqrt{\mathrm{MSE}_{\mathrm{VFA}}^{\mathrm{C}-\mathrm{V}}} \\
\mathrm{Q} 2_{\mathrm{VFA}}^{\mathrm{C}-\mathrm{V}}=100\left[1-\frac{\mathrm{MSE}_{\mathrm{VFA}}^{\mathrm{C}-\mathrm{V}}}{\operatorname{var}(\mathrm{VFA})}\right] .
\end{gathered}
$$

The $\mathrm{Q} 2_{\mathrm{VFA}}^{\mathrm{C}-\mathrm{V}}$ value should be interpreted as follows: a negative value means the model is useless, a value of 0 means it performs as well as a model returning the mean observation, a value between 0 and 100 indicates usefulness to some extent, and 100 means perfect prediction.

The overall prediction accuracy was calculated as the mean accuracy of all 3 VFA:

$$
\begin{array}{r}
\mathrm{MSE}^{\mathrm{C}-\mathrm{V}}=\frac{\mathrm{MSE}_{\mathrm{AC}}^{\mathrm{C}-\mathrm{V}}+\mathrm{MSE}_{\mathrm{PR}}^{\mathrm{C}-\mathrm{V}}+\mathrm{MSE}_{\mathrm{BU}}^{\mathrm{C}-\mathrm{V}}}{3} ; \\
\mathrm{MSE}^{\mathrm{C}-\mathrm{V}}=\frac{\mathrm{MSE}_{\mathrm{AC}}^{\mathrm{C}-\mathrm{V}}+\mathrm{MSE}_{\mathrm{PR}}^{\mathrm{C}-\mathrm{V}}+\mathrm{MSE}_{\mathrm{BU}}^{\mathrm{C}-\mathrm{V}}}{3} ; \\
\mathrm{RMSE}^{\mathrm{C}-\mathrm{V}}=\frac{\mathrm{RMSE}_{\mathrm{AC}}^{\mathrm{C}-\mathrm{V}}+\mathrm{RMSE}_{\mathrm{PR}}^{\mathrm{C}-\mathrm{V}}+\mathrm{RMSE}_{\mathrm{BU}}^{\mathrm{C}-\mathrm{V}}}{3} ;
\end{array}
$$

$$
\mathrm{Q} 2^{\mathrm{C}-\mathrm{V}}=\frac{\mathrm{Q} 2_{\mathrm{AC}}^{\mathrm{C}-\mathrm{V}}+\mathrm{Q} 2_{\mathrm{PR}}^{\mathrm{C}-\mathrm{V}}+\mathrm{Q} 2_{\mathrm{BU}}^{\mathrm{C}-\mathrm{V}}}{3} .
$$

\section{Finding the Best OBCFA Combination}

Incorporating all available OBCFA in Equations 1 to 3 does not necessarily lead to the best prediction of the respective model, as increasing the number of OBCFA in the model also increases the risk of overfitting. Traditional stepwise variable subset selection approaches are known to suffer from 3 main shortcomings. First, using the same data for model selection and coefficient estimation can lead to overfitting and biased coefficient estimation (Hurvich and Tsai, 1990; Steyerberg et al., 1999). Second, $P$-value-based hypothesis tests on the model coefficients are not really suited to perform variable selection (Johnson, 1999). Third, the stepwise approach does not guarantee that the overall optimal variable combination is found. To overcome these limitations, we (1) evaluated each OBCFA subset through $\mathrm{C}-\mathrm{V}$, (2) used model prediction accuracy rather than $P$-value hypothesis tests, and (3) investigated a large number of subsets. 
For LIN and QUAD, a separate model is used for each VFA, leading to a total of $2^{7} \times 3=384$ possible OBCFA combinations, which are all easily examined. For RAT, all 3 VFA are coupled, leading to $2^{7 \times 3}(>2$ million) possible combinations; investigating all of them is not feasible. Instead, we used 2 different approaches. When comparing the 2 different optimization methods for the rational model (Nelder-Mead and BFGS), we investigated the $2^{7}=128$ subsets that had the same OBCFA set for all 3 VFA. When finding the best OBCFA subset to compare the rational model to the linear, we used a random search that analyzed 10,000 different OBCFA subsets for the rational model.

\section{Extending the Model with a Study Effect}

As shown in Table 1, our data originates from 13 different trials, which can be grouped into 9 independent studies, which were either performed at different research facilities or at distinctly different times (or both). Protocols for VFA sampling or analysis (or both) were different in the 9 clusters, and it is possible that this resulted in a different measurement offset for each study. Estimating the study effect from the data directly before modeling was not possible, as none of the experiments was actually repeated with multiple protocols. Instead, we modified the model in a way that a different intercept was accepted for each of the studies. For the LIN, this corresponded to transforming Equation 1 into Equation 11, where $\alpha_{0}, \pi_{0}$, and $\beta_{0}$ stand for study-specific intercepts, of which the values are estimated separately for each of the study clusters:

$$
\begin{aligned}
& \widehat{\mathrm{AC}}=\alpha_{0}+\sum_{\mathrm{i}} \mathrm{a}_{\mathrm{i}} \cdot \mathrm{OBCFA}_{\mathrm{i}} \\
& \widehat{\mathrm{PR}}=\pi_{0}+\sum_{\mathrm{i}} \mathrm{p}_{\mathrm{i}} \cdot \mathrm{OBCFA}_{\mathrm{i}} \\
& \widehat{\mathrm{BU}}=\beta_{0}+\sum_{\mathrm{i}} \mathrm{b}_{\mathrm{i}} \cdot \mathrm{OBCFA}_{\mathrm{i}}
\end{aligned}
$$

This is done analogously for the QUAD:

$$
\begin{aligned}
& \widehat{\mathrm{AC}}=\alpha_{0}+\sum_{i=1}^{m_{A C}} a_{i} \cdot \text { OBCFA }_{i}+\sum_{i=1}^{m_{A C}} \sum_{j=1}^{m_{A C}} a_{i j} \cdot \text { OBCFA }_{i} \cdot \text { OBCFA }_{j} ; \\
& \widehat{P R}=\pi_{0}+\sum_{i=1}^{m_{P R}} p_{i} \cdot \text { OBCFA }_{i}+\sum_{i=1}^{m_{P R}} \sum_{j=1}^{m_{P R}} p_{i j} \cdot \text { OBCFA }_{i} \cdot \text { OBCFA }_{j} ; \\
& \widehat{B U}=\beta_{0}+\sum_{i=1}^{m_{B U}} b_{i} \cdot \text { OBCFA }_{i}+\sum_{i=1}^{m_{B U}} \sum_{j=1}^{m_{B U}} b_{i j} \cdot \text { OBCFA }_{i} \cdot \text { OBCFA }_{j} \cdot
\end{aligned}
$$

and for the RAT:

$$
\begin{aligned}
& \widehat{\mathrm{AC}}=\alpha_{0} \\
& +1,000 \frac{\sum_{\mathrm{i}} \mathrm{a}_{\mathrm{i}} \cdot \mathrm{OBCFA}_{\mathrm{i}}}{\sum_{\mathrm{i}} \mathrm{a}_{\mathrm{i}} \cdot \text { OBCFA }_{\mathrm{i}}+\sum_{\mathrm{i}} \mathrm{p}_{\mathrm{i}} \cdot \mathrm{OBCFA}_{\mathrm{i}}+\sum_{\mathrm{i}} \mathrm{b}_{\mathrm{i}} \cdot \mathrm{OBCFA}_{\mathrm{i}}} \\
& \widehat{\mathrm{PR}}=\pi_{0} \\
& +1,000 \frac{\sum_{\mathrm{i}} \mathrm{p}_{\mathrm{i}} \cdot \mathrm{OBCFA}_{\mathrm{i}}}{\sum_{\mathrm{i}} \mathrm{a}_{\mathrm{i}} \cdot \mathrm{OBCFA}_{\mathrm{i}}+\sum_{\mathrm{i}} \mathrm{p}_{\mathrm{i}} \cdot \mathrm{OBCFA}_{\mathrm{i}}+\sum_{\mathrm{i}} \mathrm{b}_{\mathrm{i}} \cdot \mathrm{OBCFA}_{\mathrm{i}}} \\
& \widehat{\mathrm{BU}}=-\alpha_{0}-\pi_{0} \\
& +1,000 \frac{\sum_{\mathrm{i}} \mathrm{b}_{\mathrm{i}} \cdot \mathrm{OBCFA}_{\mathrm{i}}}{\sum_{\mathrm{i}} \mathrm{a}_{\mathrm{i}} \cdot \text { OBCFA }_{\mathrm{i}}+\sum_{\mathrm{i}} \mathrm{p}_{\mathrm{i}} \cdot \mathrm{OBCFA}_{\mathrm{i}}+\sum_{\mathrm{i}} \mathrm{b}_{\mathrm{i}} \cdot \mathrm{OBCFA}_{\mathrm{i}}}
\end{aligned}
$$

Note that in Equation 13 for BU, the intercept was not included as a separate coefficient, but set equal to the additive inverse of the sum of the other 2 intercepts. This was done to respect the proportional nature of the VFA and guarantee that $\mathrm{AC}+\mathrm{PR}+\mathrm{BU}=1,000$ $\mathrm{mmol} / \mathrm{mol}$.

Study-specific intercepts (further called study effects) can be coded both as fixed or random effects. The use of random effects is advisable, as it increases the precision of model coefficient estimates and improves prediction (St-Pierre, 2001). However, for the RAT, which is a coupled multi-response model that is nonlinear in the parameters, we were not able to find any modeling platform [R, SAS (SAS Institute Inc., Cary, NC), or Matlab (The MathWorks Inc., Natick, MA)] that allowed incorporating a random effect into the model. Therefore, for RAT we had to restrict ourselves to a fixed study effect. For LIN and QUAD, incorporating a random study effect was possible, and the nlme package in $\mathrm{R}$ (Pinheiro et al., 2011) was used. We also investigated the prediction performance of LIN and QUAD with a fixed study effect, to get an idea of the differences of both study effect types. In total, we investigated 8 different modeling approaches: LIN, QUAD, and RAT with no study effect; LIN, QUAD, and RAT with a fixed study effect; and LIN and QUAD with a random study effect.

\section{Visualizing Distributions with Box Plots}

Throughout the manuscript, we have used box plots (Tukey, 1977) to visualize empirical distributions. A box plot shows the observations between the 25 th percentile (lower border) and the 75th percentile (upper border) in a box. Vertical lines (whiskers) extend the box in both directions to the most extreme data point that is no more than 1.5 times the interquartile range. The interquartile range is the difference between the 25 th and 
75th percentile, and it corresponds to the length of the box. Box plots show entire distributions and should not be confused with confidence intervals on the mean. To find out whether means differ significantly, box plots are not suited, statistical tests should be used instead. Box plots were drawn using the ggplot2 package (Wickham, 2009) in R (R Development Core Team, 2011).

\section{RESULTS AND DISCUSSION}

\section{Optimization Method}

From the 2 investigated methods to estimate the rational model coefficients, BFGS delivered the best prediction performance, in combination with 500 and 2,500 iterations for the model without study effect and the model with fixed study effect, respectively. Setting the initial coefficient values $\left(\mathrm{a}_{\mathrm{i}}, \mathrm{p}_{\mathrm{i}}\right.$, and $\left.\mathrm{b}_{\mathrm{i}}\right)$ in the model equal to 1 (and thereby giving equal initial importance to each OBCFA) worked well for the model without study effect. The same approach, combined with zero initial values for the study effects $\left(\alpha_{0}, \pi_{0}\right.$, and $\left.\beta_{0}\right)$ led to high $\mathrm{RMSE}^{\mathrm{C}-\mathrm{V}}$ values for the resulting model with study effect, indicating that the strong increase in the number of coefficients $(+18)$ posed a challenge to the optimization algorithm. However, an alternative approach did prove successful for the model with fixed study effect: combining zero initial study effects $\left(\alpha_{0}\right.$, $\pi_{0}$, and $\left.\beta_{0}\right)$ with initial coefficients $\left(\mathrm{a}_{\mathrm{i}}, \mathrm{p}_{\mathrm{i}}\right.$, and $\mathrm{b}_{\mathrm{i}}$ ) equal to the optimal coefficient values of the model without study effect.

\section{Comparison of the 8 Modeling Approaches}

The box plots in Figure 2 show the distribution of $\mathrm{RMSE}_{\mathrm{VFA}}^{\mathrm{C}-\mathrm{V}}$ for 100 bootstrap replicates of the data, revealing both prediction accuracy as well as precision for all investigated method/study effect combinations. The variance of the results can be seen to be comparable for all methods. Both new models (QUAD and RAT) improved prediction performance compared with the original (LIN). Paired $t$-tests showed that these improvements were statistically (highly) significant (Table 2 ). For the 3 VFA together (and for AC and PR separately), the best prediction accuracy was obtained by QUAD with study effects. Second came RAT with study effects, which is the only model that has the additional property that all 3 VFA sum up to $1,000 \mathrm{mmol} /$ mol. For BU separately, LIN with study effects gave the best prediction performance.

The worst predictions were obtained by the 3 models without study effect, showing the presence of such an effect in the data, and the need to account for it in the model. We had expected a random effect to increase the precision of coefficient estimates and improve the prediction performance (St. Pierre, 2001), which it generally did, but only to a limited extent. Most probably the limited difference was due to the fact that each $\mathrm{C}-\mathrm{V}$ fold contained observations from all studies, which was necessary to get an estimate of the study effect.

Table 3 shows the median RMSE ${ }^{\mathrm{C}-\mathrm{V}}$ and $\mathrm{Q}^{\mathrm{C}-\mathrm{V}}$ values for each modeling method. With the best model, an $\mathrm{RMSE}^{\mathrm{C}-\mathrm{V}}$ of $16.3 \mathrm{mmol} / \mathrm{mol}$ was obtained for $\mathrm{AC}, 15.6$
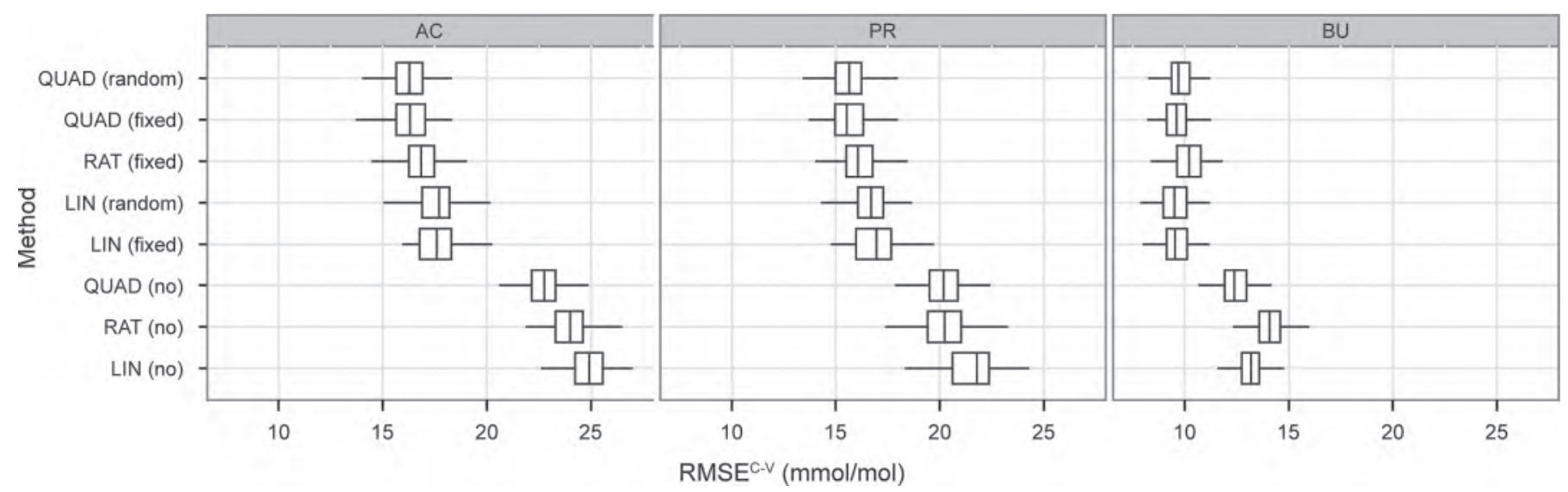

Figure 2. Box plots showing the distribution of the root mean squared cross-validation $(\mathrm{C}-\mathrm{V})$ error $\left(\mathrm{RMSE}_{\mathrm{VFA}}^{\mathrm{C}-\mathrm{V}}\right)$ for $100 \mathrm{bootstrap}$ replicates of the data. Results are shown for the 3 models [linear model (LIN), rational model (RAT), and a model with quadratic terms and interaction effects (QUAD)], the 3 settings of the study effect (no, fixed, and random), and the 3 VFA [acetate (AC), propionate (PR), and butyrate (BU)]. From top to bottom, results are ordered by increasing $\mathrm{RMSE}^{\mathrm{C}-\mathrm{V}}$. 
Table 2. $P$-values of paired $t$-tests comparing the bootstrap root mean squared error (RMSE) results of the new methods [model with quadratic terms and interaction effects (QUAD) and rational model (RAT)] to the original method [linear model (LIN) $]^{1}$

\begin{tabular}{llccc}
\hline & & \multicolumn{3}{c}{$P$-value } \\
\cline { 3 - 5 } $\begin{array}{l}\text { Original method } \\
\text { (study effect) }\end{array}$ & $\begin{array}{l}\text { New method } \\
\text { (study effect) }\end{array}$ & $\mathrm{AC}$ & $\mathrm{PR}$ & $\mathrm{BU}$ \\
\hline LIN (random) & QUAD (random) & $1.8 \times 10^{-18}$ & $8.7 \times 10^{-12}$ & $4.3 \times 10^{-8}$ \\
& QUAD (fixed) & $4.5 \times 10^{-15}$ & $2.6 \times 10^{-12}$ & $3.1 \times 10^{-1}$ \\
& RAT (fixed) & $5.5 \times 10^{-7}$ & $9.7 \times 10^{-5}$ & $4.9 \times 10^{-10}$ \\
LIN (no) & QUAD (no) & $1.5 \times 10^{-37}$ & $3.8 \times 10^{-14}$ & $1.3 \times 10^{-11}$ \\
& RAT (no) & $6.3 \times 10^{-11}$ & $6.1 \times 10^{-12}$ & $1.4 \times 10^{-17}$ \\
\hline${ }^{1} \mathrm{AC}=$ acetate; PR $=$ propionate; BU = butyrate. & &
\end{tabular}

$\mathrm{mmol} / \mathrm{mol}$ for $\mathrm{PR}$, and $9.7 \mathrm{mmol} / \mathrm{mol}$ for BU. This corresponds to $2.4 \%$ of the observed mean for $\mathrm{AC}, 7.3 \%$ for $\mathrm{PR}$, and $6.8 \%$ for $\mathrm{BU}$. The $\mathrm{Q} 2^{\mathrm{C}-\mathrm{V}}$ value reveals that with these results the cross-validated predictions managed to capture $74 \%$ of the variance in $\mathrm{AC}, 67 \%$ in $\mathrm{PR}$, and $63 \%$ in BU. These performances seem to be better than those achieved by Morvay et al. (2011), who used feed characteristics to predict molar proportions of VFA and reported RMSE values that were 2 to 3 times as large: $7.2 \%$ of the observed mean for AC, $14.4 \%$ for $\mathrm{PR}$, and $20.2 \%$ for BU. However, it is difficult to say whether our models really perform better than that of Morvay et al. (2011), as both models were tested on different data, using a different protocol to assess prediction performance. It was not possible to apply their models to our data, as the feed characteristics in our data did not include all variables required by these models. Using our models on their data, on the other hand, was not possible either, as their data did not contain milk OBCFA measurements. Therefore, it remains to be tested which variables (milk OBCFA or feed characteristics) have a higher prediction potential with respect to the rumen VFA proportions. If both turn out to have similar prediction performances, models based on feed characteristics should be preferred, as they allow calculations a priori and need fewer samplings.
Finally, Figure 3 shows the $\mathrm{C}-\mathrm{V}$ performance of the best model (QUAD with random study effect) in terms of the VFA residuals (i.e., observed minus predicted) plotted against the predicted values. The horizontal lines in each plot indicate the standard deviation of the respective VFA.

\section{OBCFA Subset Selection}

The best OBCFA subset for each of the 8 modeling approaches and each of the 3 VFA is shown in Table 4. Results for random and fixed effects were identical (within a particular method/VFA combination). As we discussed in the previous section, a study effect is needed for proper prediction, so we suggest focusing on the upper part of Table 4. Some interesting observations can be made. The more complex methods (RAT and QUAD) managed to give better predictions with less OBCFA (only 2 or 3 per VFA). With the exception of $\mathrm{C} 17$ for $\mathrm{BU}$, the best OBCFA combination of QUAD was always a subset of the best combination for LIN. This means that the results of LIN and QUAD were related, but QUAD was more efficient: it managed to achieve better prediction performance than LIN with fewer predictors. The best OBCFA combination of RAT compared well with the best combination of QUAD.

Table 3. Median root mean squared cross-validation $(\mathrm{C}-\mathrm{V})$ error $\left(\mathrm{RMSE}^{\mathrm{C}-\mathrm{V}}\right)$ and the percentage of variance that could be predicted by the model $\left(\mathrm{Q} 2^{\mathrm{C}-\mathrm{V}}\right)$ of 100 bootstrap replicates of the data ${ }^{1}$

\begin{tabular}{|c|c|c|c|c|c|c|c|c|}
\hline Model $^{2}$ & $\begin{array}{l}\text { Study } \\
\text { effect }\end{array}$ & \multicolumn{4}{|c|}{$\operatorname{RMSE}^{\mathrm{C}-\mathrm{V}}(\mathrm{mmol} / \mathrm{mol})$} & \multicolumn{3}{|c|}{$\mathrm{Q} 2^{\mathrm{C}-\mathrm{V}}$} \\
\hline QUAD & Random & 13.9 & 16.3 & 15.6 & 9.7 & 74.1 & 67.2 & 63.4 \\
\hline RAT & Fixed & 14.4 & 16.8 & 16.1 & 10.2 & 72.4 & 65.4 & 59.3 \\
\hline LIN & Random & 14.6 & 17.7 & 16.7 & 9.5 & 69.5 & 62.7 & 64.6 \\
\hline LIN & Fixed & 14.7 & 17.6 & 17.0 & 9.5 & 69.8 & 61.5 & 61.5 \\
\hline LIN & No & 20.0 & 24.9 & 21.8 & 13.2 & 39.5 & 36.5 & 32.3 \\
\hline
\end{tabular}

${ }^{1} \mathrm{AC}=$ acetate $\mathrm{PR}=$ propionate; $\mathrm{BU}=$ butyrate.

${ }^{2} \mathrm{QUAD}=$ model with quadratic terms and interaction effects; $\mathrm{RAT}=$ rational model; LIN = linear model. 

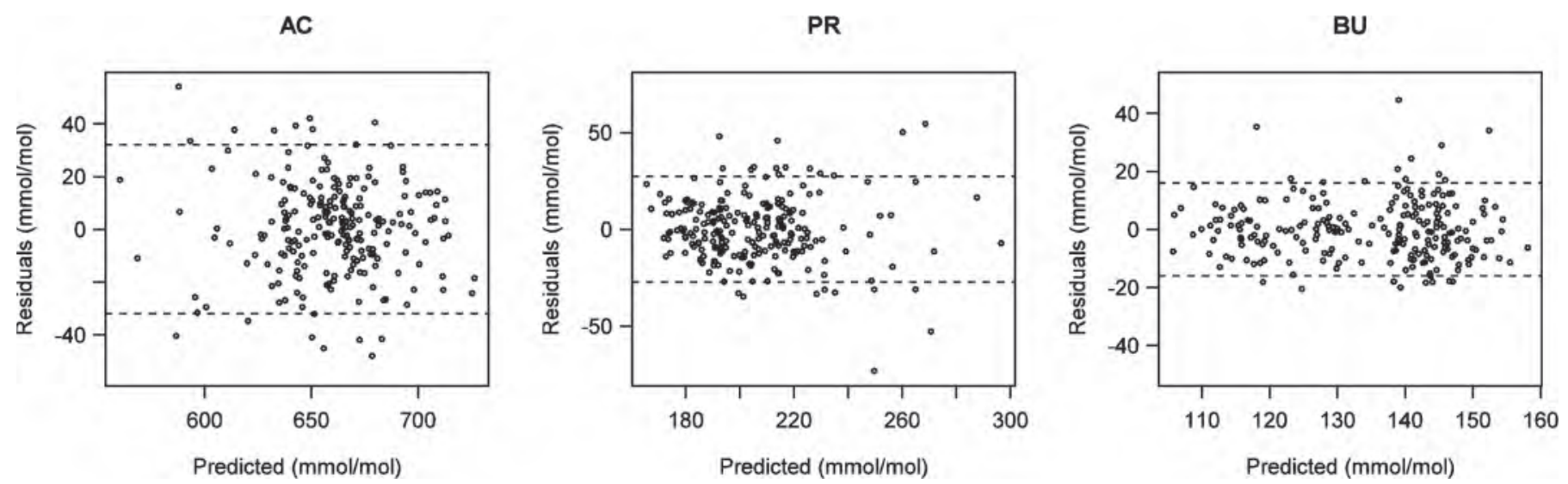

Figure 3. Predicted VFA values versus residuals (i.e., observed minus predicted) for the model with quadratic terms and interaction effects (QUAD) with a random study effect. The horizontal lines in each plot indicate the standard deviation of each VFA. AC $=$ acetate; PR $=$ propionate; $\mathrm{BU}=$ butyrate.

Finally, it is important to note that we performed OBCFA subset selection purely from a prediction perspective: we looked for the OBCFA combination that gave the best prediction. Combinations of OBCFA different from the ones listed in Table 4 can give similar (though slightly worse) prediction performances. To rank the OBCFA according to their importance, a robust variable subset selection needs to be performed. This could be done by repeating the OBCFA subset selection for 100 different bootstrap replicates of the data, and counting for each OBCFA the frequency of occurrence in the best OBCFA combination.

\section{Best Final Models}

The 7-fold $\mathrm{C}-\mathrm{V}$ procedure produces 7 different models, each being built with a subset in which one-seventh of the data was omitted. Yet, for practical purposes, a single final model is required. This was built using the best identified subset for each VFA (Table 4), and

Table 4. Best odd- and branched-chain FA (OBCFA) subset for every method and VFA ${ }^{1}$

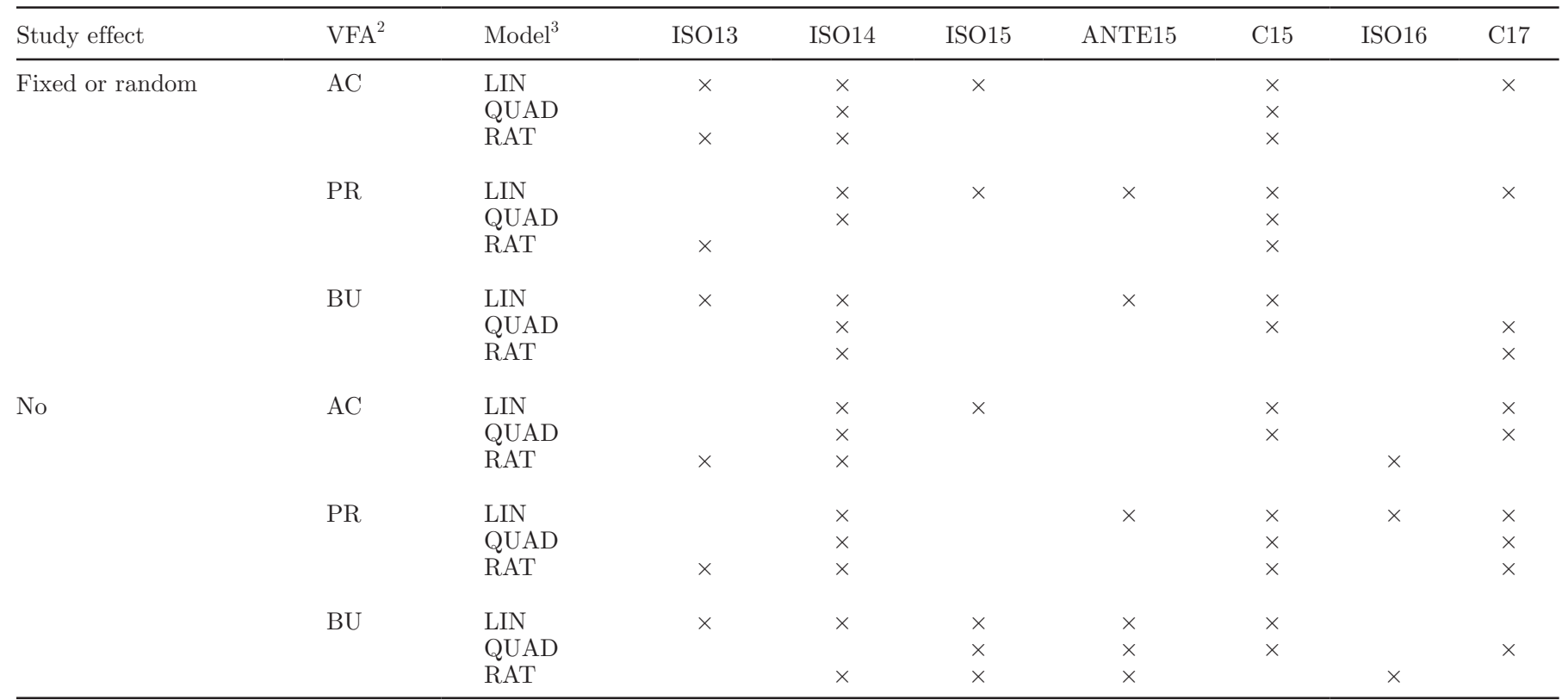

${ }^{1}$ ISO13 = iso C13:0; ISO14 = iso C14:0; ISO15 = iso C15:0; ANTE15 = anteiso C15:0; C15 = C15:0; ISO16 = iso C16:0; C17 = sum of C17:0 and $\mathrm{C} 17: 1$ cis-9.

${ }^{2} \mathrm{AC}=$ acetate; $\mathrm{PR}=$ propionate; $\mathrm{BU}=$ butyrate.

${ }^{3} \mathrm{LIN}=$ linear model; QUAD = model with quadratic terms and interaction effects; RAT $=$ rational model. 
Table 5. Intercept values for the final model with quadratic terms and fixed and random study effects $(\mathrm{QUAD})^{1}$

\begin{tabular}{|c|c|c|c|c|c|c|c|}
\hline \multirow{2}{*}{$\begin{array}{l}\text { Study } \\
\text { effect }\end{array}$} & \multirow[b]{2}{*}{ Study } & \multicolumn{2}{|c|}{$\mathrm{AC}$} & \multicolumn{2}{|c|}{$\mathrm{PR}$} & \multicolumn{2}{|c|}{$\mathrm{BU}$} \\
\hline & & Value & $\mathrm{SE}$ & Value & $\mathrm{SE}$ & Value & $\mathrm{SE}$ \\
\hline Random & All & 675 & 45.6 & 121 & 43.6 & 160 & 37.6 \\
\hline \multirow[t]{9}{*}{ Fixed } & 1 & 663 & 45.7 & 128 & 43.9 & 164 & 37.9 \\
\hline & 2 & 664 & 45.1 & 141 & 43.4 & 152 & 37.3 \\
\hline & 3 & 698 & 45.7 & 111 & 43.9 & 148 & 37.6 \\
\hline & 4 & 708 & 46.0 & 96 & 44.2 & 155 & 38.0 \\
\hline & 5 & 644 & 45.2 & 142 & 43.4 & 170 & 37.3 \\
\hline & 6 & 672 & 45.3 & 107 & 43.6 & 177 & 37.7 \\
\hline & 7 & 685 & 44.2 & 114 & 42.5 & 156 & 37.1 \\
\hline & 8 & 665 & 45.3 & 115 & 43.5 & 175 & 37.6 \\
\hline & 9 & 694 & 45.6 & 106 & 43.8 & 155 & 38.0 \\
\hline
\end{tabular}

${ }^{1} \mathrm{AC}=$ acetate $\mathrm{PR}=$ propionate; $\mathrm{BU}=$ butyrate

its coefficients were estimated using all data. The final model for the best modeling method (QUAD with study effects) is shown in Tables 5 and 6 . Table 5 shows the intercept values, whereas Table 6 shows the values of the slope coefficients. Coefficient values are shown for QUAD with fixed as well as random study effect, and the standard error on the coefficient values is also mentioned.

Differences in intercept values between studies in Table 5 can be explained well by differences in observed VFA distributions in Figure 4. Examples are the high intercept values of AC for studies 4, 3, and 9 (Table 5), for which the observed AC distributions were markedly higher than average (Figure 4). Similar explanations can be found for other studies and other VFA.
Table 6 shows that the type of study effect used (fixed or random) does not have a large effect on coefficient values or standard errors. Standard errors on some of the slope coefficients are high compared with the coefficient values. This indicates that it might be useful to drop some of the terms in the final model. This will increase the bias component of the prediction error, but decrease its variance.

\section{How to Use the Models with Study Effect}

Models with a study effect can be used in 2 different ways. When comparisons are made among data that were obtained from the same protocols for VFA sampling and analysis, the study-specific intercepts

Table 6. Slope coefficient values for the final model with quadratic terms and fixed and random study effects (QUAD) $)^{1}$

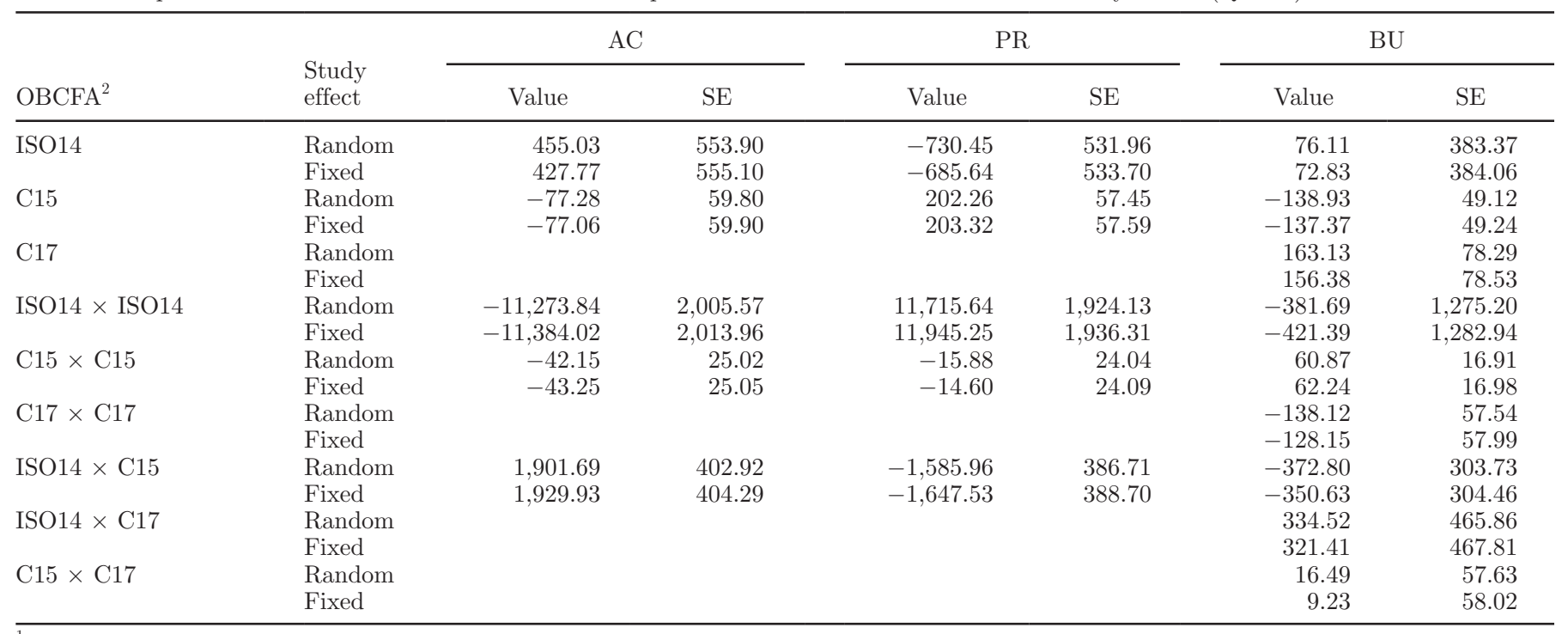

${ }^{1} \mathrm{AC}=$ acetate $\mathrm{PR}=$ propionate $; \mathrm{BU}=$ butyrate.

${ }^{2} \mathrm{OBCFA}=$ odd- and branched-chain FA; ISO14 = iso C14:0; C15 = C15:0; C17 = sum of C17:0 and C17:1 cis-9; ISO14 = iso C14:0. 

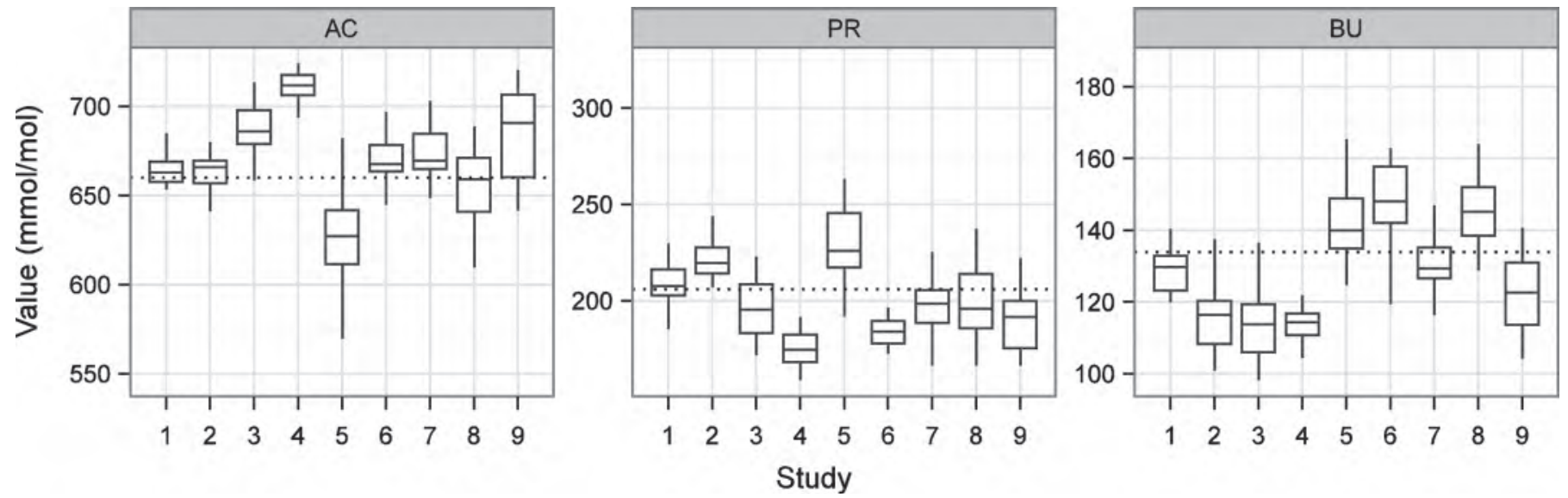

Figure 4. Box plots showing the observed distribution of each VFA within every study listed in Table 1. The dotted lines show the overall mean value. $\mathrm{AC}=$ acetate; $\mathrm{PR}=$ propionate; $\mathrm{BU}=$ butyrate.

will cancel, and the model can be used directly without any additional coefficient estimation. Examples include data gathered from the same research institute (if the same protocols were maintained) and historical data.

When data originate from different protocols, or when the actual VFA levels (and not their differences) are required, the study effect needs to be estimated first. Data from a limited number of rumen-fistulated animals should be sufficient, as now only 2 (RAT) or 3 (LIN and QUAD) coefficients remain to be estimated. The fully determined model can then be used to predict the VFA proportions for the animals that were not fistulated.

\section{CONCLUSIONS}

We introduced 2 new models to predict VFA proportions in lactating dairy cows from milk OBCFA levels: QUAD and RAT. We used C-V to identify the best OBCFA subset and assess the prediction performance of each model with its best subset. Both QUAD and RAT improved prediction significantly compared with the previously described LIN. Incorporating a studyeffect in the model improved prediction performance substantially for all models. The type of study effect used (fixed vs. random) only had a minor effect on prediction. Although RAT guarantees a constant sum of the 3 VFA, QUAD with study effects gave the best prediction: an $\mathrm{RMSE}^{\mathrm{C}-\mathrm{V}}$ of $16.3 \mathrm{mmol} / \mathrm{mol}$ for $\mathrm{AC}$, $15.6 \mathrm{mmol} / \mathrm{mol}$ for $\mathrm{PR}$, and $9.7 \mathrm{mmol} / \mathrm{mol}$ for $\mathrm{BU}$, corresponding to $2.4,7.3$, and $6.8 \%$ of the respective observed means, explaining 74,67 , and $63 \%$ of the respective variances. The study effect coefficients are eliminated when the model is used to calculate differences within the same study. When their estimation is required, VFA measurements from a limited number of animals should be sufficient. Overall, our results demonstrate the potential of using milk OBCFA to predict rumen VFA proportions.

\section{ACKNOWLEDGMENTS}

We thank the Flemish Institute for the Promotion of Innovation by Science and Technology (IWT, Flanders, Belgium) and the AAC-consortium [Agrifirm (Meppel, the Netherlands), Cehave Landbouwbelang Voeders BV (Veghel, the Netherlands), and ForFarmers Group BV (Lochem, the Netherlands)] for their funding, which made this research possible. B. Vlaeminck is a postdoctoral fellow of the Fund for Scientific ResearchFlanders (Belgium).

\section{REFERENCES}

Abrahamse, P. A., B. Vlaeminck, S. Tamminga, and J. Dijkstra. 2008. The effect of silage and concentrate type on intake behavior, rumen function, and milk production in dairy cows in early and late lactation. J. Dairy Sci. 91:4778-4792. http://dx.doi.org/10.3168/ jds.2008-1350.

Bergman, E. N. 1990. Energy contributions of volatile fatty acids from the gastrointestinal tract in various species. Physiol. Rev. 70:567-590.

Broyden, C. G. 1970. The convergence of a class of double-rank minimization algorithms. IMA J. Appl. Math. 6:76-90. http://dx.doi. org/10.1093/imamat/6.1.76.

Bruinenberg, M. H., H. Valk, P. C. Struik, and A. M. van Vuuren. 2004. Fermentation and degradation in the rumen of dairy cows fed on diets consisting of silage from an intensively managed sward and silages from semi-natural grasslands. J. Agric. Sci. 142:79-88. http://dx.doi.org/10.1017/S0021859604004046.

Colman, E., W. B. Fokkink, M. Craninx, J. R. Newbold, B. De Baets, and V. Fievez. 2010. Effect of induction of subacute ruminal acidosis on milk fat profile and rumen parameters. J. Dairy Sci. 93:4759-4773. http://dx.doi.org/10.3168/jds.2010-3158.

Craninx, M., V. Fievez, B. Vlaeminck, and B. De Baets. 2008. Artificial neural network models of the rumen fermentation pattern in dairy cattle. Comput. Electron. Agric. 60:226-238. http://dx.doi. org/10.1016/j.compag.2007.08.005. 
de Brabander, D. L., S. de Campeneere, J. M. Vanacker, and N. E. Geerts. 2005. Effect of rumen escape starch in maize silage based diets for dairy cattle. Page 134 in Book of Abstracts of the 56th Annual Meeting of the European Association for Animal Production, Uppsala, Sweden. Y. van der Honing, ed. Wageningen Academic Publishers, Wageningen, the Netherlands.

de Brabander, D. L., N. E. Geerts, S. de Campeneere, and J. M. Vanacker. 2004. Effect of starch content of maize silage based diets for dairy cattle. Page 97 in Book of Abstracts of the 55th Annual Meeting of the European Association for Animal Production, Bled, Slovenia. Y. van der Honing, ed. Wageningen Academic Publishers, Wageningen, the Netherlands.

Dewhurst, R. J., W. J. Fisher, J. K. S. Tweed, and R. J. Wilkins 2003. Comparison of grass and legume silages for milk production. 1. Production responses with different levels of concentrate. J. Dairy Sci. 86:2598-2611. http://dx.doi.org/10.3168/jds.S00220302(03)73855-7.

Fievez, V., B. Vlaeminck, M. S. Dhanoa, and R. J. Dewhurst. 2003. Use of principal component analysis to investigate the origin of heptadecenoic and conjugated linoleic acids in milk. J. Dairy Sci. 86:4047-4053. http://dx.doi.org/10.3168/jds.S00220302(03)74016-8.

Fletcher, R. 1970. A new approach to variable metric algorithms. Comput. J. 13:317-322. http://dx.doi.org/10.1093/comjnl/13.3.317.

Gervais, R., B. Vlaeminck, E. Colman, and V. Fievez. 2011. Fast-gas chromatography analysis: Perspectives on the resolution of oddand branched-chain fatty acids. Adv. Anim. Biosci. 2:350.

Goldfarb, D. 1970. A family of variable-metric methods derived by variational means. Math. Comput. 24:23-26. http://dx.doi. org/10.1090/S0025-5718-1970-0258249-6.

Hastie, T., R. Tibshirani, and J. Friedman. 2009. The Elements of Statistical Learning: Data Mining, Inference, and Prediction. 2nd ed. Springer-Verlag, New York, NY.

Hindle, V. A., A. M. van Vuuren, A. Klop, A. A. Mathijssen-Kamman, A. H. van Gelder, and J. W. Cone. 2005. Site and extent of starch degradation in the dairy cow-A comparison between in vivo, in situ and in vitro measurements. J. Anim. Physiol. Anim. Nutr. (Berl.) 89:158-165. http://dx.doi.org/10.1111/j.14390396.2005.00560.x.

Hurvich, C. M., and C.-L. Tsai. 1990. The impact of model selection on inference in linear regression. Am. Stat. 44:214-217.

Johnson, D. H. 1999. The insignificance of statistical significance testing. J. Wildl. Manage. 63:763-772.

Loncke, C., I. Ortigues-Marty, J. Vernet, H. Lapierre, D. Sauvant, and P. Nozière. 2009. Empirical prediction of net portal appearance of volatile fatty acids, glucose, and their secondary metabolites ( $\beta$-hydroxybutyrate, lactate) from dietary characteristics in ruminants: A meta-analysis approach. J. Anim. Sci. 87:253-268. http://dx.doi.org/10.2527/jas.2008-0939.

Moorby, J. M., R. J. Dewhurst, R. T. Evans, and J. Danelón. 2006. Effects of dairy cow diet forage proportion on duodenal nutrient supply and urinary purine derivative excretion. J. Dairy Sci. 89:35523562. http://dx.doi.org/10.3168/jds.S0022-0302(06)72395-5.

Morvay, Y., A. Bannink, J. France, E. Kebreab, and J. Dijkstra. 2011. Evaluation of models to predict the stoichiometry of volatile fatty acid profiles in rumen fluid of lactating Holstein cows. J. Dairy Sci. 94:3063-3080. http://dx.doi.org/10.3168/jds.2010-3995.

Nelder, J. A., and R. Mead. 1965. A simplex method for function minimization. Comput. J. 7:308-313. http://dx.doi.org/10.1093/ comjnl/7.4.308.

Nozière, P., F. Glasser, and D. Sauvant. 2011. In vivo production and molar percentages of volatile fatty acids in the rumen: A quantitative review by an empirical approach. Animal 5:403-414.

Pinheiro, J, D. Bates, S. DebRoy, D. Sarkar, and the R Development Core Team. 2011. nlme: Linear and Nonlinear Mixed Effects Models. R package version 3.1-102. Accessed Aug. 1, 2011. http:// cran.r-project.org/web/packages/nlme/index.html.

R Development Core Team. 2011. R: A Language and Environment for Statistical Computing. R Foundation for Statistical Computing, Vienna, Austria. Accessed Aug. 1, 2011. http://www.R-project. org.

Shanno, D. F. 1970. Conditioning of quasi-Newton methods for function minimization. Math. Comput. 24:647-656. http://dx.doi. org $/ 10.2307 / 2004840$.

St-Pierre, N. R. 2001. Invited review: Integrating quantitative findings from multiple studies using mixed model methodology. J. Dairy Sci. 84:741-755.

Stefanov, I., V. Baeten, O. Abbas, E. Colman, B. Vlaeminck, B. De Baets, and V. Fievez. 2010. Analysis of milk odd and branched chain fatty acids using Fourier Transform (FT)-Raman spectroscopy. J. Agric. Food Chem. 58:10804-10811. http://dx.doi. org/10.1021/jf102037g

Steyerberg, E. W., M. J. Eijkemans, and J. D. Habbema. 1999. Stepwise selection in small data sets: A simulation study of bias in logistic regression analysis. J. Clin. Epidemiol. 52:935-942.

Sutton, J. D., M. S. Dhanoa, S. V. Morant, J. France, D. J. Napper, and E. Schuller. 2003. Rates of production of acetate, propionate, and butyrate in the rumen of lactating dairy cows given normal and low-roughage diets. J. Dairy Sci. 86:3620-3633. http:// dx.doi.org/10.3168/jds.S0022-0302(03)73968-X.

Tukey, J. 1977. Exploratory Data Analysis. Addison-Wesley, Boston, MA.

Vlaeminck, B., C. Dufour, A. M. van Vuuren, A. R. J. Cabrita, R. J. Dewhurst, D. Demeyer, and V. Fievez. 2005. Use of odd and branched-chain fatty acids in rumen contents and milk as a potential microbial marker. J. Dairy Sci. 88:1031-1042. http://dx.doi. org/10.3168/jds.S0022-0302(05)72771-5.

Vlaeminck, B., V. Fievez, A. R. J. Cabrita, A. J. M. Fonseca, and R. J. Dewhurst. 2006a. Factors affecting odd- and branched-chain fatty acids in milk: A review. Anim. Feed Sci. Technol. 131:389-417. http://dx.doi.org/10.1016/j.anifeedsci.2006.06.017.

Vlaeminck, B., V. Fievez, S. Tamminga, R. J. Dewhurst, A. van Vuuren, D. De Brabander, and D. Demeyer. 2006b. Milk odd- and branched-chain fatty acids in relation to the rumen fermentation pattern. J. Dairy Sci. 89:3954-3964. http://dx.doi.org/10.3168/ jds.S0022-0302(06)72437-7.

Wickham, H. 2009. ggplot2: Elegant graphics for data analysis. Springer, New York, NY. Accessed Aug. 1, 2011. http://had. co.nz/ggplot2/book. 